\title{
HITLER, A HISTÓRIA E A HISTORIOGRAFIA
}

LUKACS, John. O Hitler da História. Trad. de Ruy Jungmann.

Rio de Janeiro: Jorge Zahar Ed., 1998, 250p.

\section{Francisco César Alves Ferraz ${ }^{1}$}

Adolf Hitler foi, sem dúvida, a personalidade mais importante da história do século $\mathrm{XX}$. Por mais que possamos reagir com merecida indignação a qualquer esforço de legitimação ou reabilitação dos atos que, direta ou indiretamente, desencadeou, não podemos negar que, para o bem e para o mal, o século que está terminando não seria o mesmo sem ele e o que ele representou e ainda representa.

Mas o que significa a trajetória de um único homem no fluir da história? Pergunta interessante, sempre presente nas discussões sobre a biografia como uma modalidade do conhecimento histórico. Nos bancos escolares, aprendemos que homens sozinhos não fazem a história, mas grupos sociais (sejam estes classes, estamentos, grupos políticos, religiosos, étnicos, etc). Mas será que o caso de Hitler se encaixa neste princípio geral? Afinal, qual o lugar de Hitler na história da Alemanha, da Europa e do século XX?

Essas e outras questões importantíssimas para o entendimento da história mais recente da civilização ocidental são a base para $O$ Hitler da História, livro de John Lukacs, historiador húngaro radicado nos Estados Unidos. Nele, o autor analisa a imensa variedade de biografias e estudos sobre Adolf Hitler, uma massa historiográfica que soma mais de uma centena de títulos, se ficarmos apenas nas obras consideradas "mais sérias" ou de maior repercussão.

Lukacs inicia seu rigoroso balanço das biografias e interpretações sobre Hitler com um pressuposto básico: embora moralmente compreensível, a demonização de Hitler não contribui em nada para entender seu papel na história. Mais do que

Professor-Assistente do Departamento de História da Universidade Estadual de LondrinaPR

Hist. Ensino, Londrina, v. 5, p. 169-176, out. 1999 
simplesmente condenar Hitler pelos males da guerra e do nazismo, é preciso compreendê-lo historicamente, cotejar as fontes documentais, entender os influxos do passado e do presente nas interpretações sobre o líder nazista.

Somos apresentados, assim, a um debate que envolveu historiadores que procuravam entender o fenômeno Hitler e, ao mesmo tempo, entender o lugar dos alemães naquele passado. Esse debate foi marcado ideologicamente pela Guerra Fria e seus maniqueísmos. Enquanto historiadores "de esquerda" procuravam definir Hitler e o nazismo ora como fenômenos da extrema-direita alemã e européia, ora como decorrências históricas do imperialismo capitalista, outros, auto-denominados "conservadores", procuravam explicar o Terceiro Reich como uma anomalia, um desvio da história alemã, ou mesmo como uma resposta histórica a um mal maior, que seria representado pelo então totalitarismo comunista. Na esteira dessas variadas interpretações, documentos de toda espécie eram invocados para corroborar tais afirmações, enquanto outros seriam desprezados por negá-las ou colocá-las em dúvida.

Dessa maneira, o leitor é sempre lembrado de que não basta ser uma interpretação tradicional ou mesmo inovadora, se ela não estiver respaldada em metodologias e aparatos documentais coerentes e abrangentes. Neste ponto, Lukacs é particularmente ácido nas críticas a obras que, nos meios acadêmicos brasileiros, são bastante prestigiadas, como Origens do Totalitarismo, de Hannah Arendt (que critica pelo uso arbitrário e assistemático de fontes, "cheio de falhas e desonesto") e Ascensão e Queda do Terceiro Reich, de William Shirer ("superficial e germanófobo").

Após esse breve balanço, Lukacs elegeu alguns problemas históricos e historiográficos da vida de Hitler e qual a relação desses com a história da Alemanha e do mundo na primeira metade do século $X X$. Alguns desses problemas são tão fundamentais como polêmicos, para o entendimento do lugar de Hitler na história.

a) As idéias e crenças de Hitler a respeito da política, dos 
judeus e do papel da Alemanha no mundo consolidaram-se em Munique, após a primeira Guerra Mundial.

Para Lukacs, se existem indícios suficientes para apontar o período vienense como a base para o seu germanismo e antisemitismo, a consolidação dessas idéias e a luta para transformálas em realidade, porém, só puderam acontecer após a derrota alemã e o fracasso da revolução comunista na Baviera em 1919. Em Munique, Hitler descobriu ser um orador de talento, e que suas idéias encontravam ressonância: o repertório de ódios explícitos aos judeus, aos comunistas, aos "traidores da Alemanha", aos inimigos de Versalhes (p.60-61) encontrou terreno fértil na Baviera e, depois, no resto do país.

b) Hitler foi, a seu modo, mais revolucionário do que reacionário.

Depois de discorrer sobre os problemas da definição do que é ser revolucionário e/ou reacionário, Lukacs afirma algo que apenas alguns inimigos contemporâneos a Hitler (como Winston Churchill) intuíram: Hitler era perigoso por ser revolucionário, e não por ser reacionário. Muitas das idéias de Hitler eram modernas. Em que pese seus métodos, sob sua liderança, a Alemanha transformou-se numa potência econômica e tecnológica mais respeitável do que era antes da Primeira Guerra Mundial, com auto-estima e prosperidade recuperadas (p.78). E dentre os ingredientes da modernidade de Hitler, estava sua habilidade para conquistar tanto as classes conservadoras quanto as massas em um mesmo discurso de transformação e mudança. Nas palavras de Lukacs,

O que isso significa para o passado recente $o$ historiador pode - e tem o dever - de reconhecer: que Hitler foi um novo tipo de revolucionário, um revolucionário populista em uma era democrática, não obstante os elementos mais antigos das instituições e da sociedade alemã ainda existentes em sua época, muitas das quais ele sabia usar para seus próprios fins (p.88).

c) Ele era mais nacionalista que racista. 
Embora a questão racial fosse fundamental para toda sua ideologia, sua racionalidade política buscava, quando the convinha, apoio em japoneses, chineses, árabes, croatas, romenos, etc, desde que isso significasse auxílio no combate aos inimigos dos "arianos" (p.94). Além disso, a despeito de não se encontrar claramente uma definição diferencial de Hitler se a "Raça Ariana"ou a "Nação Alemã" é que iria governar seu mundo, existem indícios suficientes de que seu pensamento e ação elegiam a Nação Alemã, concebida sob prisma mais cultural que biológico. A Nação seria a realização histórico-cultural do Volk (Povo), liderada não por um Estado tradicional de funcionários públicos, mas por um Volkgenossenstaat, um "Estado de camaradagem do Povo". Assim, segundo Lukacs, diferenças entre arianos e negros, amarelos, etc não chamavam tanto a atenção de Hitler quanto àquela que dizia respeito à "luta dentro da raça branca, entre arianos e judeus". Os judeus seriam sua obsessão, por viverem entre os "legítimos membros da nação alemã". E nesse ponto, seu ódio obsessivo aos que considerava "inimigos da nação" era insuperável (p.98).

d) De certa maneira, Hitler foi um estadista e estrategista competente

Assim como o êxito do líder alemão deveu-se, em grande parte, à sua subestimação pelos seus inimigos e aliados de ocasião, muitos historiadores desprezam-no a priori como estadista e estrategista. Lukacs, no capítulo mais longo do livro, recoloca em discussão o problema. Para ele, Hitler demonstrou, principalmente no período que antecedeu a guerra, atitudes de estadista que eram esperadas de líderes de potências européias daquele tempo. Embora condenáveis moralmente, sua política possuia uma certa racionalidade na adequação dos meios (muitas vezes ultrajantes) para os fins que se propunha. $\mathrm{Na}$ Alemanha de Hitler, a política interna e externa se apoiavam mutuamente.

Do ponto de vista estratégico, suas decisões, se examinadas friamente, tiveram sucessos retumbantes embora, a longo prazo, terminassem em fracassos flagrorosos. Apesar da oposição de alguns generais do Exército, a prioridade às forças terrestres de rápida mobilidade não apenas garantiu as vitórias 
iniciais alemãs como contribuiu para drásticas mudanças nas doutrinas de guerra de então. Mesmo aquele que é apontado como como seu maior equívoco estratégico - a criação da Segunda Frente, ao invadir a União Soviética - pode ser entendido a partir da suposição de Hitler de que as principais potências capitalistas (Inglaterra e Estados Unidos) hesitariam em combater mortalmente a nação que pudesse subjugar a ameaça bolchevique. Lukacs chama a atenção para documentos que mostram que, até as vésperas do fim, Hitler acreditava que a aliança "improvável" entre o Ocidente capitalista e a potência comunista poderia ser rompida (p.115 e segs.). E conclui com uma ressalva: se por um lado sentiu-se "obrigado a enfatizar que ele [Hitler] possuía talentos políticos e militares", por outros, esses "coexistiam com obsessões não raro fanáticas". Além disso, embora Hitler não tenha sido o autor de todas as decisões e ações do Terceiro Reich, ele sabia que suas principais diretrizes eram cumpridas fielmente. E por isso é que "ele foi sem dúvida responsável pelas maldades mais brutais cometidas por seus esbirros (p.126)".

e) Não há como dissociar Hitler da "Solução Final" dos Judeus.

Embora tenha havido tentativas, como a de David Irving, de eximir Hitler de qualquer responsabilidade de planejar e ordenar a execução em massa dos judeus (afirmando que quem planejara e ordenara tudo foram os auxiliares de Hitler, sem seu conhecimento e autorização), o que a vasta documentação e as interpretações mostram é que ele ordenou - ou pelo menos consentiu com - o extermínio em massa dos judeus, o que ficou conhecido como a "Solução Final". Se não foi encontrada sua "assinatura" em documentos dessas espécie, isso só prova uma coisa: havia um mínimo de consciência de que o que se estava cometendo era uma atrocidade sem pararelos, e isso obviamente não podia ser documentado, ainda mais na iminência de uma invasão aliada (p.135). O que merece ser ainda melhor pesquisado é o quanto a população germânica realmente sabia sobre os campos de concentração e sobre a "Solução Final" e como quem sabia de algo lidava com isso. 
f) Hitler foi parte da história alemã, e não um "desvio" acidental e indesejável.

Segundo Lukacs, há entre os alemães uma tendência em ver Hitler como um episódio antinatural na história do país. No entanto, o Terceiro Reich representou muito mais uma continuidade do que uma aberração na história alemã. Isso não quer dizer que Hitler e o nazismo seriam inevitáveis. Mas a ascensão de Hitler e as crenças e atitudes do povo alemão da primeira metade do século estavam intimamente interligadas:

O nacionalismo e a unidade nacional alemã constituíram também forças poderosas durante a I Guerra Mundial. Hábitos nacionais profundamente enraizados de obediência e disciplina persistiram e culminaram na II Guerra Mundial. A estrutura psíquica (e social) dos sucessos do povo alemão na II Guera Mundial, porém, mudou, e isto foi tanto condição quanto resultado da ação de Hitler. Sem Hitler, os alemães não poderiam ter conseguido o que conseguiram, e Hitler tampouco poderia ter realizado o que realizou sem o povo alemão - ou mais exatamente, sem a aceitação esmagadora de sua pessoa pela maioria (p.142).

É preciso separar o movimento historiográfico de "reabilitação" de Hitler e dos alemães sob o Terceiro Reich das tentativas conhecidas como "revisionistas". Esses últimos sequer podem ser considerados como dignos de figurar no debate historiográfico, pois além da pobreza e má fé documental de seus escritos, são sectários escrevendo para um número limitado de leitores, que já estavam convencidos de antemão ou prontos para sê-lo (p.156). De outra natureza são especialistas, alguns com assento nas universidades e institutos de pesquisa e que, inadvertidamente ou não, tentam minimizar os apectos sombrios do Reich e de Hitler, bem como distribuir responsabilidades para outros agentes históricos, como no caso do desencadear da II Guerra Mundial, atribuída aos "objetivos bélicos e inflexível má vontade de seus inimigos". No entanto, Lukacs não aprofunda 
os porquês de tal posicionamento. Talvez, o que se deve perguntar é como o clima da Guerra Fria e de anti-comunismo contribuiu para justificar e promover aberrações interpretativas como essas...

Trata-se, portanto, de um balanço histórico e historiográfico de grande importância, para todos aqueles que se interessam por conhecer melhor Hitler e o nazismo, bem como o debate historiográfico a respeito. É uma obra admirável, de estilo agradável e que aprofunda pontos bastante polêmicos de nossa história mais recente. Para não ficar apenas nos elogios, acredito que pelo menos dois problemas devem ser comentados, embora não comprometam a grandeza do conjunto.

Um deles é seu sistemático desprezo às abordagens marxistas sobre seu tema. Embora tenha alguma razão ao apontar a pouca variação dos argumentos marxistas, ele não desenvolve nehuma discussão aprofundada sobre quais seriam os equívocos dessa corrente, preferindo refugiar-se no chavão de que o marxismo padece de determinismo econômico, como se não existissem abordagens bem distantes desses lugarescomuns.

O outro problema é que, depois de passar o livro todo chamando a atenção para a necessidade de abordagens sem demonizações de qualquer espécie, discorre ao final sobre as "características malignas espirituais" de Hitler, e propõe "a necessidade de uma interpretação cristã de Adolf Hitler (p. 180 e p. 240 , n. 49 e segs.)". Particularmente, prefiro sua proposta inicial, de que por mais que provoque nossa indignação moral, é preciso compreendê-lo historicamente, e não como o Anticristo ou a emanação do Mal em seu estado mais absoluto.

Mostrar a crueldade, a monstruosidade e tudo o que é mais abjeto, obscuro e inumano no nazismo é imprescindível, mas nunca será o suficiente. Por mais de 50 anos partilhamos a condenação moral do que acreditamos ser a origem da maior tragédia do século. No entanto, seu espectro resiste, se fortalece e se diversifica (como os grupos neonazis, skinheads, nacionalistas de extrema-direita e os defensores de "limpezas étnicas", por exemplo), num mundo sem utopias libertadoras e 
regido pelo pensamento único do mercado. Até agora nos satisfizemos em condenar o nazismo. O desafio, para o presente e o futuro, é compreendê-lo. Mais do que um avanço historiográfico, é um ato de militância pela dignidade da política. E este livro proporciona considerável contribuição para isso. 